\title{
Capsule Commentary on Yoong et al., A Cross-sectional Study Examining Australian General Practitioners' Identification of Overweight and Obese Patients
}

\author{
Ramona DeJesus, MD \\ Department of Internal Medicine, Mayo Clinic, Rochester, MN, USA.
}

J Gen Intern Med 29(2):359

DOI: $10.1007 / \mathrm{s} 11606-013-2671-2$

(c) Society of General Internal Medicine 2013

$\mathrm{G}$ lobally, the prevalence of obesity and overweight has reached epidemic proportions, leading to substantial morbidity/mortality and becoming a significant public health issue. ${ }^{1}$ Primary care physicians and general practitioners are well positioned to make a difference in the battle against obesity through early recognition and intervention in the at-risk patient population.

This study by Yoong et al., ${ }^{2}$ conducted in several practice sites in urban Australian cities, examined the accuracy of general practitioners (GPs) in identifying overweight and obese patients using as reference self-reported weight and height by patients. Yoong et al. also looked into GPs and patient characteristics associated with non-detection of overweight and obesity. They found GPs' estimation of overweight and obesity to be $7 \%$ and $8 \%$ lower, respectively, than estimates based on patients' self-report; the sensitivity of GP assessment was only $63 \%$, whereas specificity was $89 \%$. College-educated, male, non-diabetic, normotensive patients had higher odds of non-detection. There was no significant GP characteristic identified. The authors cited factors that may account for these observations, and recommended that strategies to help GPs improve identification of obese and overweight be initiated.

The subjects in this study electronically entered height and weight from which body mass index (BMI) was calculated, but the GPs had no access to this data; instead, they were asked to complete a hard copy questionnaire answering "Yes or "No" to a list of patient's health risk conditions, such as alcohol consumption, obesity, smoking, and overweight. This was done to minimize reporting bias if GPs were only queried on obesity and overweight. Yet, having data such as BMI available to primary care providers (PCPs) and GPs through electronic clinical support tools and reminders may be effective strategies that can improve clinician recognition and early intervention. Their use has been shown to improve practitioner outcomes in chronic disease management and delivery of preventive care services. ${ }^{3-5}$ Tapping into new information and communication technologies can help busy practitioners stay ahead in the race to decrease the burden of chronic diseases that obesity exemplifies. What impact providers can have on reducing or preventing obesity or what interventions are effective remain unknown and should be the focus of future research.

Corresponding Author: Ramona DeJesus, MD; Department of Internal Medicine, Mayo Clinic, Rochester, MN 55905, USA (e-mail: Dejesus.ramona@mayo.edu).

\section{REFERENCES}

1. Stevens GA, Singh GM, Lu Y, Danaei G, et al. National, regional and global trends in adult overweight and obesity prevalences. Popul Health Metr. 2012 Nov 20;10(1):22.

2. Yoong SZ, Carey ML, Sanson-Fisher RW, D'Este CA, Mackenzie L, Boyes A. A Cross-sectional study examining Australian general practitioners' identification of overweight and obese patients. J Gen Intern Med 2013; doi: 10.1007/s11606-013-2637-4.

3. Garg AX, Adhikari NK, McDonald H, Rosas-Arellano MP, et al. Effects of computerized clinical decision support systems on practitioner performance and patient outcomes: a systematic review. JAMA. 2005 Mar 9;293(10): 1223-38.

4. Baron RC, Melillo S, Rimer BK, Coates RJ, et al. Intervention to increase recommendation and delivery of screening for breast, cervical and colorectal cancers by healthcare providers a systematic review of provider reminders. Am J Prev Med. 2010 Jan;38(1):110-7.

5. Benhamou PY. Improving diabetes management with electronic health records and patients' health records. Diabetes Metab. 2011 Dec;37(Suppl 4):S53-6. 